REVIEW

\title{
Involvement of nurses in euthanasia: a review of the literature
}

\author{
T De Beer, C Gastmans, B Dierckx de Casterlé
}

J Med Ethics 2004;30:494-498. doi: 10.1136/ime.2003.004028

In ethical debates about euthanasia, the focus is often exclusively on the involvement of physicians and the involvement of nurses is seldom given much attention. Yet nurses occupy a central position in the care of terminal patients, where being confronted with a euthanasia request is an ever present possibility. To assess the involvement of nurses in euthanasia, this article provides an overview of relevant findings from the scientific literature. From this it becomes apparent that nurses are involved in various phases of the euthanasia process: observing the request for euthanasia, decision making, carrying out of euthanasia, and the aftercare for the patient's family members.

See end of article for authors' affiliations

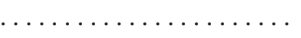

Correspondence to: Ms T De Beer, 91

Gravenbosstraat, Liedekerke, B-1770, Belgium; tina.debeer@ advalvas.be

Received 14 April 2003

In revised form

10 July 2003

Accepted for publication

7 August 2003
I n ethical debates about euthanasia, the focus is often exclusively on the involvement and responsibilities of physicians; the involvement of nurses is seldom given much attention. Although euthanasia may be one of the so called medical decisions surrounding the end of life, it is still an issue that greatly affects nurses. They are the ones who are involved on a daily basis in the care of dying patients. In hospitals they are at patients' bedsides 24 hours a day. This permanent, caring involvement with terminally ill patients teaches nurses a great deal about patients' anxieties, questions, and needs. ${ }^{1}$ Consequently, a nurse being confronted with a patient's request for euthanasia would not be such an unlikely occurrence.

On 16 May 2002, the Belgian parliament definitively approved the legislative bill on euthanasia. The law came into force on 23 September 2002. This makes Belgium the second country (after the Netherlands) to have a law on euthanasia. Even though there is currently legal regulation of euthanasia in Belgium and the Netherlands, very little is known about the involvement of Belgian and Dutch nurses in euthanasia. Some insight into their actual involvement in the process of euthanasia would nevertheless be useful when drawing up guidelines for clinical practice.

Sometimes cases come to light in which nurses have administered a lethal injection at the request of a patient, without the knowledge of the physician and/or the patient's family. Such practices usually garner extensive media attention and some have claimed that this kind of nursing practice is more widespread than is generally thought. Disturbing messages like this cause confusion about the position of nurses in euthanasia. For this reason, too, empirical research that would clarify nurses' involvement in euthanasia is long overdue.

These considerations have prompted us to carry out a literature review on the topic. By integrating existing empirical findings, this article will attempt to sketch a general picture of how nurses, internationally, are involved in euthanasia (however, judging the permissibility of nurses' involvement in euthanasia falls outside the scope of this article).

In this article, the term "euthanasia" means "the administration of lethal drugs with the explicit intention of shortening the patient's life at the patient's explicit request". This is the definition that is used in the Belgian and Dutch euthanasia laws. ${ }^{2}$

By "the involvement of nurses in euthanasia", we mean the role played by the nurse in cases where a patient requests euthanasia. This involvement is not at all limited to providing assistance in administering the lethal medication, but includes the nurse's role throughout the entire process of euthanasia. This process comprises registering the request for euthanasia, participation in decision making, actually performing the euthanasia, and aftercare. ${ }^{3}$ The nurse's involvement in euthanasia does not refer to the attitudes and ideas of nurses regarding euthanasia or their own involvement in it. Although these attitudes and ideas may conceivably exercise an influence on a nurse's factual involvement, they fall outside the scope of this literature review. By restricting this study to the actual involvement of nurses in euthanasia, we hope to provide a more focused picture of that involvement.

\section{METHOD}

The literature was systematically investigated using the electronic databases Medline and Cinahl from 1970 to June 2002, and using the snowball method.* We also consulted an expert in the field. In selecting the literature, three criteria were applied: (1) articles which describe the results of (quantitative or qualitative) empirical research; (2) articles focused on the involvement of nurses in euthanasia; (3) English, French, or Dutch language publications.

At first sight, there appears to be a great deal of literature on the involvement of nurses in euthanasia, but after a thorough analysis of the content of these articles, the number of usable

*Examining the references for further articles; examining those articles' references, and so on. 
publications was drastically reduced. In a large number of the publications it was unclear what was meant by euthanasia, or else the definition used did not comply with the definition of euthanasia proposed for this study. Moreover, most authors limited themselves to a description of the nurses' attitudes and ideas about euthanasia and their involvement in it.

The search strategy yielded 15 usable studies which then formed the basis for this literature review. Fourteen articles describe the results of a quantitative empirical investigation, and provide mainly statistical information. One article describes the results of a qualitative empirical study in which an attempt was made to understand what this involvement really implies. ${ }^{3}$

In nine articles, the sample consisted of nurses. ${ }^{3-11}$ These studies were considered as primary articles in the literature review. The samples consisted exclusively of palliative care nurses, intensive care nurses, and oncology nurses on the one hand; and nurses from diverse fields on the other hand. The remaining six studies, in which physicians or cases of death are the topic of investigation, provide supplemental and indirect information regarding the involvement of nurses. The selected studies were carried out in the Netherlands, Belgium, Australia, Japan, and the United States.

\section{Euthanasia law}

Since April 2001, the Netherlands has had a legal regulation of euthanasia, making it the world's first country to place euthanasia within a legal framework. This regulation allows a physician to administrate lethal drugs at the voluntary and well considered request of patients (adults and children aged 12 years or older) whose suffering is lasting and unbearable. Before doing so, the physician has to inform the patient about his or her situation and prospects and has to consult another independent physician. Before April 2001, the Netherlands pursued a policy whereby euthanasia was tolerated if the physician performing it respected a number of due care requirements. Guidelines concerning cooperation and task distribution between physicians and nurses in the euthanasia process were drawn up by the Royal Dutch Medical Association (KNMG) together with the National Nurses Association (NU 91). ${ }^{12}$ One of the guidelines states that the involvement of nurses in decision making is desirable because of the nurses' specific skills and everyday involvement in patient care. The administration of the euthanaticum, however, is an action that is reserved for physicians.

In Belgium, after years of debate, the law governing euthanasia came into force on 23 September 2002. Before this date, euthanasia was illegal in Belgium. The legislation allows a physician to carry out euthanasia on adults who are in a medically futile condition of constant and unbearable physical or mental suffering that cannot be alleviated, resulting from a serious and incurable disorder caused by illness or accident. Like in the Dutch law, euthanasia can also be performed on the basis of an advanced directive. The Belgian law governing euthanasia says very little about the role of nurses in euthanasia. The euthanasia act only mentions that if there is a nursing team present that has regular contact with the patient, then the patient's euthanasia request must be discussed with this team. ${ }^{2}$ So the legislation leaves uncertainty in the minds of nurses regarding their concrete function and involvement.

In Australia, euthanasia is currently illegal. However, a 1995 law made euthanasia legal for a short time in the Northern Territory. This law, which permitted euthanasia and physician-assisted suicide under certain conditions, came into force on l July 1996, and was revoked after a debate in March 1997. ${ }^{13}$
Japanese criminal law explicitly prohibits assisted suicide or killing others at their request. Nevertheless there is still uncertainty and ambiguity regarding the legality of euthanasia. The Japanese Medical Association's Bio-ethical Council suggests that euthanasia ought to be permitted in exceptional circumstances. Moreover, the district court in Yokohama laid down four criteria which must be fulfilled in cases of euthanasia. ${ }^{11}$

Euthanasia is illegal in every state of the US, and euthanasia does not have a prominent place in the debate on the end of life that is conducted in the US. The discussion is focused mainly on assisted suicide, which is legal only in the state of Oregon. ${ }^{13}$

\section{RESULTS}

\section{Registering a request for euthanasia}

The literature studied shows that around one nurse in four has at some point been confronted with a request for euthanasia from at least one patient. Twenty five per cent of American nurses working with adult cancer patients have been confronted with a euthanasia request. In this study, the number of requests received by a nurse can vary from 0 to 20 in the year preceding the study. ${ }^{9}$ Of the nurses in a different American study (oncology and non-oncology nurses), 22\% had at some point received a euthanasia request from a patient, and the number of requests varied from 0 to 30 in the year preceding the study. ${ }^{10}$ In a study carried out in the Australian state of Victoria, $36 \%$ of nurses had at some time received a euthanasia request from a patient. ${ }^{4}$ It should be pointed out that, in addition to a request from a legally competent patient, a request by way of an advance directive also belongs to their definition of euthanasia. Another Australian study from the same period shows that 30\% of nurses in South Australia had at some point received a request from a patient for active termination of life. In this study, more men than women reported having received a request from a patient $(\mathrm{p}<0.05)$. However, the number of men in the sample was rather small, so it is unclear whether this sex discrepancy is valid for the total population of South Australian nurses. ${ }^{6}$ Studies of American intensive care nurses give a smaller number: $13 \%$ of nurses have at some point been confronted with a patient's request for euthanasia and/or assisted suicide. This may be partly due to the patients in this ward having a reduced ability to communicate. ${ }^{7}$

Qualitative research from the Netherlands shows that half of the patients use the word "euthanasia" to express their request. ${ }^{3}$ The other half uses vague terms. In this regard, the authors refer to the important role of the nurse in registering and correctly interpreting the request. Because of their specific expertise and daily involvement in the care of terminal patients, nurses are the most appropriate people to determine, together with other caregivers (including doctors), whether the request is genuinely a euthanasia request and whether the request originates from the patient himself. Research brings to light the fact that nurses do not always interpret the euthanasia request as meant by the patient. Precisely as a result of their immense personal involvement and long standing relationship with the patient, in some cases nurses go by their feelings regarding the request, without fully examining those feelings. ${ }^{3}$

Australian nurses almost always inform the other nurses (92\%) and the physician (90\%) about the patient's request to accelerate death. In $68 \%$ of cases, the family is informed. ${ }^{4} \mathrm{~A}$ study in which Japanese palliative care nurses were compared with the Australian nurses from the study just mentioned revealed comparable statistics as far as informing other nurses and the physician is concerned. On the other 
hand, the family is more frequently $(\mathrm{p}<0.0001)$ informed by Japanese nurses than by Australian nurses. ${ }^{11}$

The results of the Dutch qualitative research show that informing the physician, and especially informing other nurses, about the request usually takes place without the patient's consent ${ }^{3}$ even though, in the Netherlands, requesting consent was one of the guidelines put forward by the Royal Dutch Medical Association and the National Nurses Association. ${ }^{12}$ The authors suggest that a possible explanation for this is the fact that nurses act out of habit and are insufficiently aware of the need for extreme care in dealing with information regarding ethically sensitive issues like euthanasia. $^{3}$

\section{Participation in decision making}

Participation by nurses in decision making is usually limited to taking part in discussions; nurses seem to have very little say in the actual decision making process. In the Dutch qualitative research, nurses thought that a formal vote in decision making was not a necessity, but they did think it was important that they be heard, precisely because of their everyday involvement in terminal care and their specific expertise in the field. ${ }^{3}$

The medical literature shows, however, that participation by nurses in discussions about a euthanasia request or assisted suicide is absent in about half of the cases. ${ }^{14} 15$ Differences can be noted in the extent to which physicians consult with nurses. In the first place, the physician's specialty plays a role: Dutch specialists (in internal medicine, pulmonology, cardiology, neurology, or surgery) and nursing home physicians consult more frequently with nurses than Dutch general practitioners (GPs) in cases of euthanasia or assisted suicide. Among Dutch specialists and nursing home physicians, consultations take place in $95 \%$ of cases. On the other hand, Dutch GPs have consultations with the nurses involved in 55\% of cases. ${ }^{16}$ One possible explanation for this discrepancy put forward by the authors is the work environment. Compared with nursing home physicians or specialists, GPs usually have a more personal relationship with their patients, one in which nurses play no part. The differences in the extent to which physicians consult based on their specialty is illustrated by another Dutch study. ${ }^{17}$ As far as GPs are concerned, there were consultations in 17-40\% of reported cases of euthanasia. If one only looks at the cases in which nurses are involved in patient care, the consultation rate is $64 \%$. Among Dutch specialists (in various disciplines), this percentage is notably higher: nurses were consulted in $75-86 \%$ of cases. ${ }^{17}$

The extent of consultation between physician and nurses also varies according to the topic of consultation. In $52 \%$ of cases, Dutch GPs consulted nurses about the patient's request for euthanasia or assisted suicide when professional nurses were involved in treating the patient. Consultations were carried out to a lesser extent about the physician's intention to perform euthanasia or assisted suicide (40\%) and the physician's actually carrying it out $(36 \%) .{ }^{14}$

Respect for the patient's wishes was the primary reason given by Dutch GPs for not consulting nurses. Some of the other reasons cited were: the physician not considering it necessary to consult, lack of time, the limited involvement of nurses in care, and the physician's wish to safeguard confidentiality. ${ }^{16}$

\section{Carrying out euthanasia}

The role played by the nurse in carrying out euthanasia can vary from simple presence in person to the actual administration of the lethal medication.

In general, the nurse has a role that consists primarily in assisting the patient and family. This means good patient oriented care not only in the days and hours leading up to, but also during the administration of the lethal medication. ${ }^{3}$ One surprising finding is that Dutch homecare nurses are absent at the moment the lethal medication is administered in $90 \%$ of cases. ${ }^{16}$ In $3 \%$ of cases, the nurse is present in the house but not at the patient's bedside. This means that in 7\% of cases, homecare nurses are present at the patient's bedside during administration of the lethal medication. In a nursing home, this percentage is $60 \% .^{16}$

Although the administration of the lethal medication is usually carried out by a physician, it is sometimes delegated to a nurse. ${ }^{346-8161819}$ For instance, 21\% of Dutch specialists stated that nurses sometimes administer the lethal medication under their supervision. ${ }^{16}$ In the same study, Dutch GPs stated that the lethal medication was administered by a nurse in $4 \%$ of the cases, and in 3\% of cases for Dutch hospital physicians. An Australian study showed that 23\% of nurses had at some point been asked by the physician to administer the lethal medication, and of these, $85 \%$ had complied with the request. ${ }^{4}$ One study showed that the percentage of nurses in South Australia who ended the life of a patient in an active manner at the request of a physician was 5.4\%. ${ }^{6}$ An American study of the association between the self reported participation of intensive care nurses and their social and professional characteristics showed that older nurses, more religious nurses, nurses working in a cardiology unit, and nurses with less positive attitudes towards euthanasia are less likely to report having cooperated in performing euthanasia. ${ }^{8}$ The authors observed that the effect of the sex and religion of the nurses is probably mitigated by attitudes.

Among the reasons for physicians delegating the administration of a lethal medication, reference is often made to the nurses' technical expertise with medical drip devices (intravenous drip), the means by which a lethal medication is most often administered. Other reasons cited include habit, a wish to find the easiest solution, and the hierarchical relationship between the physician and nurse. ${ }^{3}$ Although the percentages are low, it cannot be denied that nurses sometimes carry out euthanasia without a physician having prescribed it. An Australian study showed, for instance, that 5\% of nurses working with terminal patients over 12 years of age, and who receive a euthanasia request from a patient, sometimes comply with the patient's request without authorisation from a physician. ${ }^{4}$ This figure is almost identical to the $4.5 \%$ rate among oncology nurses in an American study, and the $2 \%$ rate among nurses (mixed sample of oncology and nononcology nurses) from a separate American study. ${ }^{90}$ In the two latter studies, however, it is not clear to what extent the attending physician was involved.

Reasons cited by the nurses for performing euthanasia without a physician's authorisation include: a feeling of responsibility for the patient's wellbeing, the wish to relieve the patient of his or her suffering, and the wish to avoid therapeutic obstinacy on the part of physicians. ${ }^{4}$

Nurses generally experience their involvement in carrying out euthanasia as being quite demanding. This is primarily because of the planned nature of the patient's death, and the quick transition from life to death, which confront the nurses with a sense of unreality. ${ }^{3}$ This does not diminish the fact that nurses exhibit a relatively high degree of willingness to participate in carrying out euthanasia. ${ }^{5}$ This willingness is high for the personal presence of a supporting nurse when the lethal medication is being administered. Very few nurses, on the other hand, are prepared to administer the lethal injection themselves.

\section{Aftercare}

Data relating to aftercare can be found in the Dutch qualitative study. ${ }^{3}$ Aftercare relates to the nurses supportive role towards the deceased patient's family. After euthanasia 
is performed there is frequently an interview between the physician and the family-usually in the presence of the nurse-at which the family members can air their feelings and review the course of the illness. The physician and nurse generally have a brief discussion in which they share their experiences. $^{3}$

A thorough evaluation of the nursing aspects of the overall caring process framing euthanasia is often not sufficiently present, and sometimes entirely absent. The impression arises that nurses hardly ever reflect on their involvement in the euthanasia process. ${ }^{3}$

\section{DISCUSSION}

The aim of this literature review was to provide an international sketch of the involvement of nurses in euthanasia. Even though euthanasia is a hot topic, the amount of literature does not reflect this and what little there is has limitations. Firstly, there is a limited number of basic articles focusing on the involvement of nurses in euthanasia. The remaining articles, in which the object of study was mainly physicians and cases of death, bring the involvement of nurses to light only in an indirect manner. A second limitation has to do with the lack of information about the reliability and validity of the measurement techniques used. It is therefore advisable to use caution when interpreting and comparing research findings. Finally, the atmosphere of illegality surrounding euthanasia at the time the study was carried out is a potential source of distortion for the research findings. One could wonder whether the study's guarantee of anonymity was sufficient to allow the participants to answer freely and truthfully.

In spite of these limitations, the literature review does provide a number of valuable findings regarding nurses' involvement in euthanasia. In the first place, this study lends empirical support to the actual involvement of nurses in euthanasia. Nurses are undeniably confronted with requests for euthanasia from patients-often, they are the first caregivers to receive such a request-and this means they are more or less explicitly involved in further care of these patients. This research evidence contrasts sharply with the almost total absence of nurses in the euthanasia debate, which focuses mainly on the involvement of physicians in euthanasia.

In terms of the actual form in which nurses are involved in euthanasia, this literature review gives a less clear picture. Although one could conclude on the basis of the literature that nurses are involved in the entire process of care (from the patient's request, through performing euthanasia, to aftercare for the family) and have a number of important jobs to do, this study can only partially illustrate a few aspects of their involvement. Central among them are: listening to and interpreting the patient's request, reporting and explaining the request to other nurses and physicians, and lending support to the patient and the patient's family when carrying out euthanasia. The study further suggests that the extent and the manner in which nurses are effectively involved in care for patients with a euthanasia request are dependent on a number of contextual factors. This probably refers to the legal context in which the euthanasia request is situated, the euthanasia policy in place in the healthcare institution and respective ward, the existing structures of communication, the therapeutic policies, the physician's specialty, and the institutional setting (such as homecare, nursing home, hospital, and so on). More pragmatic factors such as time pressures and habit also seem to have a role in determining whether and in what way nurses are involved in the various phases of the care process.

The fact that the involvement of nurses in euthanasia is situation dependent contributes to an extreme lack of clarity regarding nurses' involvement, and this is somewhat troubling. Particularly when it comes to performing euthanasia, there is little clarity regarding the actual role and responsibility of nurses. In spite of the fact that responsibility lies in principle with the physicians, and nurses are given a supporting role as assistants, the nursing practice in this phase turns out to be less transparent. The atmosphere of illegality in which euthanasia was situated at the moment the studies were carried out can be a significant contributing factor to this: only in the Dutch studies was there an official policy of toleration regarding euthanasia, where the euthanasia procedure was regulated by concrete guidelines with respect to the division of labour between physician and nurses. The discovery that in some cases nurses administered the lethal medication themselves-whether or not this was delegated by the physician and in the presence of the physician-is a finding that should be taken quite seriously. It goes without saying that the lack of clarity regarding the nurse's involvement in euthanasia, as demonstrated by this study, does nothing to help care for the patients. This is even more disturbing when one realises that nurses-compared with other healthcare professionals-are best positioned to provide care for dying patients. The continuity of care and the closeness with the patient place nurses in a privileged position for listening to and registering the patient's euthanasia request, for determining what the reasons may be for the request, for reporting the request to the attending physician, for participating in discussions about the request, and for assisting and supporting the patient and family. The strong personal involvement in caring for these patients and the specific expertise in this area permit nurses to be a "skilled companion" for these patients, ${ }^{20}{ }^{21}$ a companion who is willing and competent to encounter the other as a person, to ascertain his or her needs and, together with the patient, to seek the most dignified answer in an interdisciplinary context.

The willingness to care for patients who request euthanasia is clearly present among nurses. What is much less clear from the empirical studies under review is how this willingness gets translated into care. The broad social debate on euthanasia, which in Belgium and the Netherlands has already led to a euthanasia law, leads us to believe that nurses will increasingly be confronted with euthanasia requests and will therefore be more involved in care for these patients. The results of this literature review argue for greater transparency and clarity of policy regarding actual practice, especially nursing practice. Greater awareness of and reflection on the specific contributions of nurses in caring for patients who request euthanasia could lead to a clearer picture of the nurse's role in this care. Until now, awareness of the specific contribution made by nurses in caring for these patients seems to be lacking in the social debate, in research, and in clinical practice. In other words, optimal care for patients who explicitly request euthanasia demands a better understanding of how nursing expertise and care can most effectively be employed in the interdisciplinary care context, so that the patient receives the most humane care available. Further research into the involvement of nurses in euthanasia will undoubtedly contribute to such an understanding.

The fundamental question however remains: what is the moral relevance of these empirical findings? How can empirical data about nursing involvement in euthanasia be used to carry out a normative assessment of clinical care practice? How should the relation between nursing care and euthanasia be viewed from an ethical perspective? Further research-both empirical and ethical-is necessary in order to provide good answers to the ethical questions raised by the involvement of nurses in euthanasia and to arrive at good clinical practice. 


\section{Authors' affiliations}

T De Beer, Faculty of Medicine, Centre for Health Services and Nursing Research, Catholic University of Leuven, Leuven, Belgium

C Gastmans, Faculty of Medicine, Centre for Biomedical Ethics and Law, Catholic University of Leuven, Leuven, Belgium

B Dierckx de Casterlé, Faculty of Medicine, Centre for Health Services and Nursing Research, Catholic University of Leuven, Leuven, Belgium

\section{REFERENCES}

1 Broeckaert B. België: naar een wettelijke regeling van euthanasie (Belgium: heading for a regularisation of euthanasia). Tijdschrift voor Geneeskunde en Ethiek 2001;11:62-66.

2 Belgisch Staatsblad. Wet betreffende de euthanasie (Law on euthanasia). Available from http://www.fgov.be (accessed 20 September 2002).

3 van de Scheur A, van der Arend A. The role of the nurse in euthanasia: a Dutch study. Nurs Ethics 1998;5:497-508.

4 Kuhse $\mathrm{H}$, Singer $\mathrm{P}$. Voluntary euthanasia and the nurse: an Australian survey. Int J Nurs Stud 1993;30:311-22.

5 Young A, Volker D, Rieger PT, et al. Oncology nurses' attitudes regarding voluntary, physician-assisted dying for competent, terminally ill patients. Oncol Nurs Forum 1993;20:445-51.

6 Stevens CA, Hassan R. Nurses and the management of death, dying and euthanasia. Med Law 1994;13:541-54.

7 Asch DA. The role of critical care nurses in euthanasia and assisted suicide. N Eng J Med 1996:334:1374-9.

8 Asch DA, Dekay ML. Euthanasia among US critical care nurses: practices, attitudes and social and professional correlates. Med Care 1997;35:890-900.

9 Matzo M, Emanual EJ. Oncology nurses' practices of assisted suicide and patient-requested euthanasia. Oncol Nurs Forum 1997;24:1725-32.
10 Ferrell B, Virani R, Grant $M$, et al. Beyond the Supreme court decision: nursing perspectives on end-of-life care. Oncol Nurs Forum 2000;27:445-55.

11 Tanida N, Asai A, Ohnishi M, et al. Voluntary active euthanasia and the nurse: a comparison of Japanese and Australian nurses. Nurs Ethics 2002:9.313-22.

12 Koninklijke Nederlandse Maatschappij tot bevordering der Geneeskunst \& Nieuwe Unie' 91 . Euthanasierichtlijnen arts-verpleegkundige: richtlijnen samenwerking en taakafbakening arts en verpleegkundige bij de procedure rond euthanasie (Guidelines, euthanasia for physicians and nurses: cooperation and professional tasks of physicians and nurses in euthanasia procedures). Utrecht, 1997 (third edition).

13 L'euthanasie. Available from http://www.senat.fr/lc/lc49/lc49_mono.html (accessed 10 April 2002).

14 van der Wal G. Euthanasie en hulp bii zelfdoding door huisartsen (Euthanasia and physician-assisted suicide by general practitioners). Med Contact 1991;46:171-3, 174-6, $211-15,237-41$.

15 Deliens L, Mortier F, Bilsen J, et al. End-of-life decisions in medical practice in Flanders, Belgium: a nationwide survey. Lancet North Am Ed 2000;356:1806-11.

16 Muller MT, Pijnenborg L, Onwuteaka-Philipsen BD, et al. The role of the nurse in active euthanasia and physician-assisted suicide. J Adv Nurs 1997;26:424-30

17 van der Wal G, van der Maas PJ. Euthanasie en andere medische beslissingen rond het levenseinde (Euthanasia and other medical end-of-life decisions). The Hague: Sdu, 1996.

18 Baume P, O'Malley E. Euthanasia: attitudes and practices of medical practitioners. Med J Aust 1994;161:137, 140, 142-4.

19 Meier DE, Emmons C, Wallenstein S, et al. A national survey of physicianassisted suicide and euthanasia in the United States. N Eng J Med 1998;338: 1193-201.

20 Kitson AL. Does nursing have a future? Br Med J 1996;313:1647-51.

21 Titchen A. Professional craft knowledge in patient centred nursing and the facilities of its development (doctoral dissertation). University of Oxford, UK, 2000.

\section{$\mathrm{ECHO}$}

\section{Introducing circumcision into a society will not prevent HIV infection}

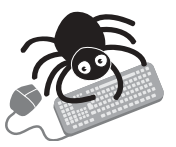

Please visit the Journal of Medical Ethics website [www. jmedethics. com] for a link to the full text of this article. ntroducing male neonatal circumcision into a non-circumcising society will almost certainly not prevent HIV infection and, in any case, needs to be undertaken with extreme care.

In a critique of a paper proposing to introduce the practice into Botswana the author shows that the idea of HIV prevention through circumcision is based on false premises. In his opinion, the reliance on circumcision to prevent HIV infection can only result in a calamitous worsening on the HIV-AIDS epidemic as it fails to place the main emphasis for prevention on safe sex.

Issues relating to circumcision include medical, psychological, sexual, and social effects, human rights, ethical, and legal aspects that must be considered and that the author explains in detail.

The practice of neonatal circumcision in certain Eastern countries, such as the United States, is to the author not a valid reason for introducing it into Botswana. Once started circumcision tends to persist even when the need is over, as is exemplified by many countries, where it is proving difficult to eradicate.

A Sexually Transmitted Infections 2003;79:427-428. 